\title{
Thoracic Wall Reconstruction in Advanced Breast Tumours
}

\section{Thoraxwandrekonstruktion bei fortgeschrittenen Tumoren der Brust}

Authors

Affiliation

\section{A. Daigeler, K. Harati, O. Goertz, T. Hirsch, B. Behr, M. Lehnhardt, J. Kolbenschlag}

Klinik für Plastische Chirurgie und Schwerbrandverletzte, Handchirurgiezentrum, Operatives Referenzzentrum für Gliedmaßentumoren, BG Universitätsklinikum Bergmannsheil, Bochum

\section{Key words \\ - deformities of the breast \\ - breast \\ - breast cancer \\ - breast carcinoma \\ Schlüsselwörter \\ - Fehlbildungen der Mamma \\ - Mamma \\ - Mammamalignom \\ - Mammakarzinom}

Deutschsprachige Zusatzinformationen online abrufbar unter: www.thieme-connect.de/ ejournals/toc/gebfra

$\begin{array}{ll}\text { received } & 1.11 .2013 \\ \text { revised } & 9.12 .2013 \\ \text { accepted } & 21.12 .2013\end{array}$

Bibliography

Dol http://dx.doi.org/

10.1055/s-0033-1360321

Geburtsh Frauenheilk 2014; 74:

548-556 (c) Georg Thieme

Verlag KG Stuttgart · New York .

ISSN 0016-5751

\section{Correspondence}

Jonas Kolbenschlag, M.D.

BG Universitätsklinikum

Bergmannsheil

Klinik für Plastische Chirurgie und Schwerbrandverletzte,

Handchirurgiezentrum,

Operatives Referenzzentrum

für Gliedmaßentumoren

44789 Bochum

Jonaskolbenschlag@gmail.com

\section{Abstract \\ $\nabla$}

In advanced mammary tumours, extensive resections, sometimes involving sections of the thoracic wall, are often necessary. Plastic surgery reconstruction procedures offer sufficient opportunities to cover even large thoracic wall defects. Pedicled flaps from the torso but also free flapplasties enable, through secure defect closure, the removal of large, ulcerated, painful or bleeding tumours with moderate donor site morbidity. The impact of thoracic wall resection on the respiratory mechanism can be easily compensated for and patients' quality of life in the palliative stage of disease can often be improved.

\section{Introduction}

$\nabla$

Large, sloughing, painful, ulcerated or bleeding breast tumours can frequently only be treated by means of extended resections. Radiotherapy and chemotherapy alone do not usually lead to sufficient containment of the local situation, leaving patients with pain or open wounds, which involve a significant restriction of quality of life, at the mercy of the progression of the local finding. On the one hand, patients dread an intervention like this and, on the other hand, doctors dissuade them from surgical treatment, so progression is accepted as being inevitable. This is a common occurrence when people are not aware of the plastic-surgery reconstruction options.

On the one hand, plastic surgery reconstructive procedures enable oncological tumour resection and, on the other hand, could make radiotherapy possible by improving the local tissue situation, or alleviate pre-existing radiotherapy effects [1-3]. Full-thickness defects can also be covered using relatively simple procedures. However, there are

\section{Zusammenfassung}

$\nabla$

Bei fortgeschrittenen Tumoren der Mamma werden oft ausgedehnte Resektionen, teilweise unter Mitnahme von Anteilen der Thoraxwand, nötig. Plastisch-chirurgische Rekonstruktionsverfahren bieten suffiziente Möglichkeiten, auch große Thoraxwanddefekte zu decken. Gestielte Lappenplastiken vom Rumpf, aber auch freie Lappenplastiken ermöglichen durch einen sicheren Defektverschluss die Entfernung großer, ulzerierter, schmerzhafter oder blutender Tumoren mit moderater Hebemorbidität. Der Einfluss der Thoraxwandteilresektion auf die Atemmechanik ist gut kompensierbar, die Lebensqualität der Patienten im oft palliativen Stadium der Erkrankung kann verbessert werden.

barely any long-term results for this procedure [4-6] and those which are available are usually restricted to survival, relapse and metastasis frequency $[7,8]$, while reports on patient satisfaction, quality of life or pulmonary function are rare $[9,10]$.

So, in the following, the options for defect coverage and reconstruction in advanced breast tumours are to be discussed using selected case studies and weighted in the context of the references.

\section{Tumour Resection and Reconstruction of the Thoracic Wall $\nabla$}

The scale of the final resection size depends primarily on the treatment approach. While rather radical resections can also make sense if the intention is curative, a careful weighing up of the radicality of the surgery and the affliction of the patient must take place, particularly when it comes to palliative situations. 
However, in the case of advanced breast tumours, when it comes to an invasion of the thoracic wall, both cases frequently require not just a soft tissue excision, but also a (partial) thoracic wall resection. When it comes to the resection of a tumour, particularly if the intention is to cure, no compromise may be made on radicality to the benefit of the emerging defect. Follow-up resections do not necessarily worsen the outcome, but the aim is always the direct and full resection of the tumour [11]. Only a sufficient tumour resection like this enables containment of the local situation and thus adequate treatment [12]. Furthermore, the established criteria of oncological surgery apply as a matter of course, e.g. with regard to the use and positioning of drains [13].

The resulting defect can be safely closed using the techniques described in the following, by which means these also enable the resection of extensive findings.

Synthetic nets are used to reconstruct the resulting thoracic wall defect for the purposes of avoiding a herniation of the intra-thoracic organs and improving the stability of the thorax. These nets should be both robust and pliable at the same time. There are a variety of materials available but, similar to the situation with implant-based reconstruction, thus far none [14] have proven significantly superior $[9,15,16]$. We have had good experience with non-absorbable prolene nets in our institution. No bony chest wall reconstruction takes place, nor even stabilisation using rigid metal or artificial ribs/sternal replacement. In the case of extensive wound infections, the synthetic net may need to be avoided at first, this may be brought in subsequently if need be and once the wound has finished healing. If the wound healing process is disrupted, an exposed net does not have to be fully resected anyway. If the infection is contained and the discharge guaranteed, overgranulation can be waited for and split skin transplanted [17].

Synthetic nets, exposed ribs or the sternum must be covered with well-perfused tissue of sufficient thickness and good skin condition. A local tissue shift in the sense of a transposition-rotation flap can close smaller defects, however, to prevent disruptions to the wound healing process, it should only take place if the tissue to be transplanted has not been pre-irradiated. In the case of larger defects and following irradiation, regional pedicled or free flap-plasties must be used to gain tissue on the irradiated region. On the torso there are several secure local flap-plasties available, which are supplied via defined blood vessels and dispose of a rotational radius suitable for reaching the upper anterior and lateral thorax.

\section{Flap-Plasties}

\section{$\nabla$}

\section{Thoracoepigastric flap}

This fascio-cutaneous flap is lifted pedicled to the perforators coming out at the proximity of the midline of the fascia of the musculus rectus abdominis and is capable of closing-up smaller defects. It can be safely lifted to the lateral clavicular line and then reaches the 3rd rib when cranially transposed. In order to improve the supply security of this flap, after localising the relevant perforator vessel using Doppler imaging, the flap can be planned and lifted based on this perforasome [18].

- Figs. 1 to 3 show a thoracoepigastric flap graft being carried out in a patient with recurrent breast cancer following an ablation.

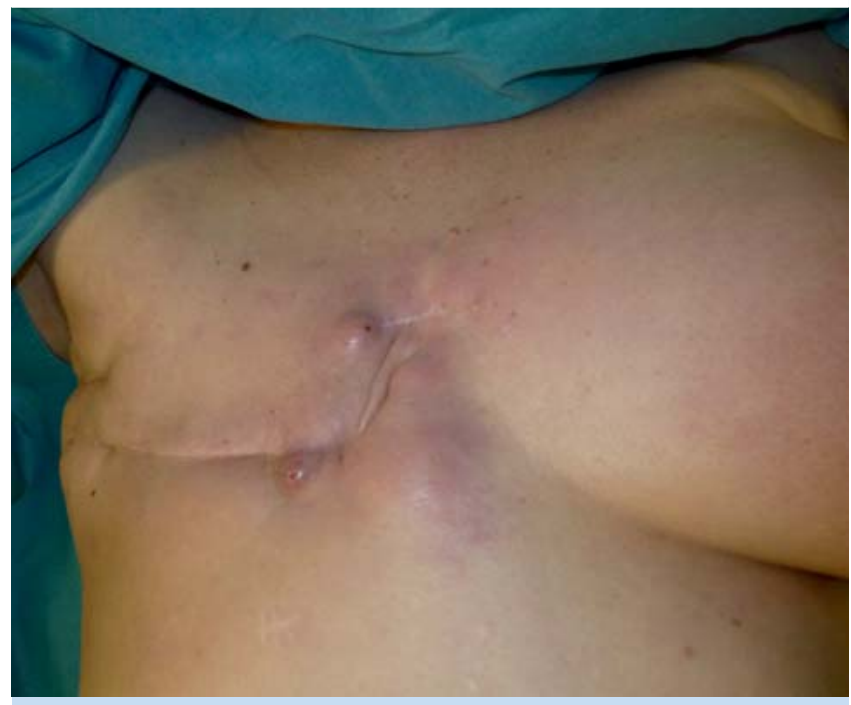

Fig. 1 Preoperative situs of a patient with recurrent breast cancer following an ablation.

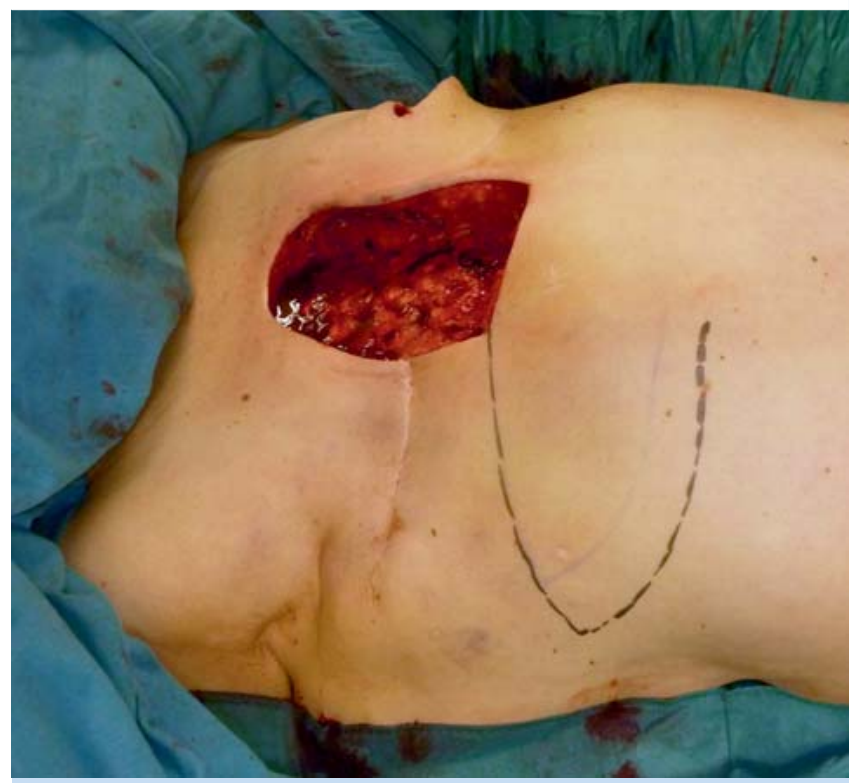

Fig. 2 Intraoperative situs following the resection of the finding and planning of a thoracoepigastric flap.

\section{Pectoralis major flap}

In principle, the pectoralis major flap can be used as a myocutaneous flap or simply as a muscular flap. In the case of a myocutaneous flap, a skin graft is also taken from the region of the lower breast fold, this graft remains pedicled to the muscle and can be transposed into the head/neck region [19]. As a result of prior operations or radiotherapy, this flap is only seldom used for ipsilateral defect coverage on the thorax. Its area of application is primarily in the field of head and neck reconstruction (myocutaneous flap) [19] or in the reconstruction of defects in the cranial portion of the sternum (muscular flap) [20]. Smaller contralateral defects may be easily reached but one constraint that must be mentioned is that while the skin graft lifted from the lower breast fold region does leave behind a donor site which is good in terms 


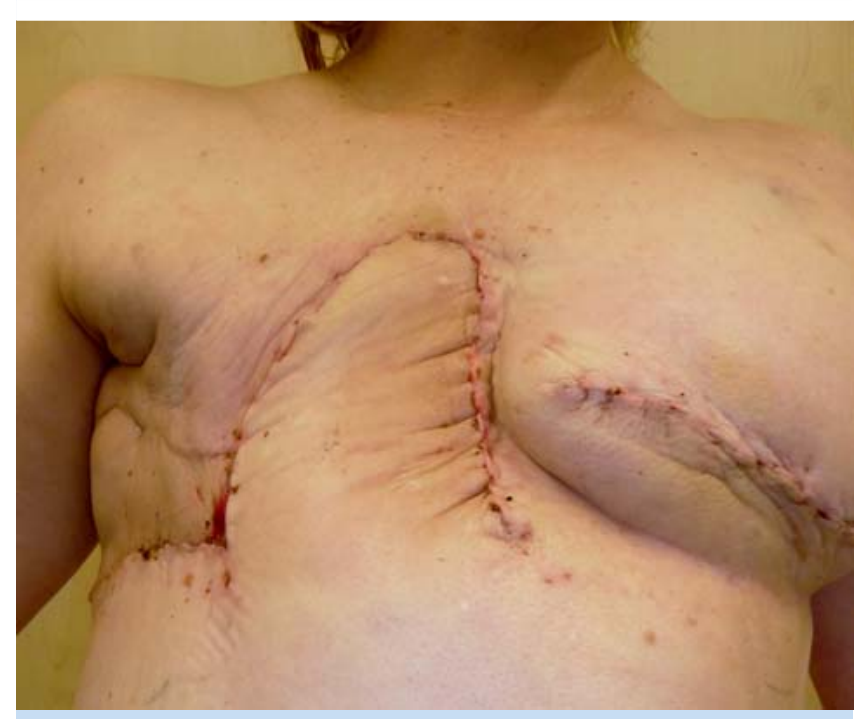

Fig. 3 Postoperative finding with fully healed flap-plasty and stable defect coverage.

of aesthetics, it has an insecure blood supply and partial flap necrosis could result from venous insufficiency, which is why we only use it in certain cases. As a flap which is simply muscular, the pectoralis major can be removed from the thoracic wall as a "sliding pectoralis flap" and, to gain more rotational freedom, it can be removed from the clavicle and the humerus too. In this case, it remains pedicled to the pectoral branches of the arteria thoracoacromialis and can thus be transposed to the defect requiring coverage $[21,22]$. Upon lifting the muscle, there is only a moderate loss of strength [20].

Pectoralis major flaps are, however, only used in the reconstruction of the thoracic wall following tumour resection under certain circumstances. Firstly, the size of the skin graft is very limited in the case of a myocutaneous flap and, secondly, the vascular structure of the flap is often impaired by prior operations, the progression of infections and radiotherapy because of where it is located.

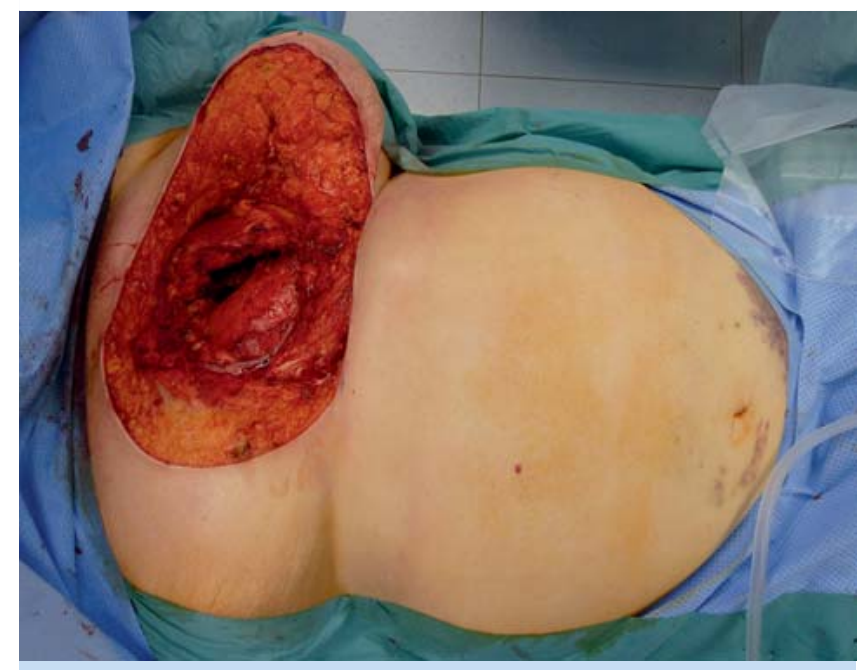

Fig. 4 Intraoperative situs following radical resectioning involving the sternum.

\section{VRAM flap}

The vertical rectus abdominis muscle flap (VRAM) is best suited to longitudinal defects due to its shape and coverage [23]. Because the VRAM is primarily supplied by the caudal continuation of the arteria epigastrica superior, the planning should take into account any possible removal of the arteria mammaria interna (usually the left) in previous coronary artery bypass operations, and the flap should be lifted contralaterally to the place of removal. An incision along the edge of the costal arch also usually involves the sectioning of the underlying superior epigastric vessels, making ipsilateral flap lifting obsolete. On rare occasions, insufficient venous outflow via the superior epigastric vessels can occur. In order to be able to react appropriately, it is advisable when lifting a flap to prepare the inferior epigastric vessels too in order to then be able to connect these parasternally to the mammaria interna vessels in the sense of "vessel supercharging". Our own follow-up studies on the VRAM flap in oncological patients showed the formation of an abdominal hernia or bulging in $13 \%$ in the long-term. All patients would choose the surgical procedure again. No flap loss was observed and the loss of strength was moderate with a slight restriction of endurance without decreased maximum strength [24].

- Figs. 4 and 5 show the case of a patient with full-thickness sternal infiltration by a CUP (cancer of unknown primary). Following radical resectioning involving the sternum, the defect was covered using a pedicled VRAM-flap.

\section{Anchor flap}

If larger defects require to be closed up which also affects the lateral thorax, the flap can be extended to include a transversal graft from the lower abdomen (transverse rectus abdominis muscle flap: TRAM). The thus resulting anchor flap can close up defects of up to $40 \mathrm{~cm}$ in diameter. In the majority of cases, the cutaneous donor site should primarily be closed by means of an abdominoplasty with umbilical repositioning where possible. The closure of the abdominal wall wound can, depending on the resulting fascia defect, be reinforced with a mesh insert in order to avoid the formation of a hernia.

In the case of this flap-plasty, the perfusion also takes place via the superior epigastric vessels which are, however, weaker in

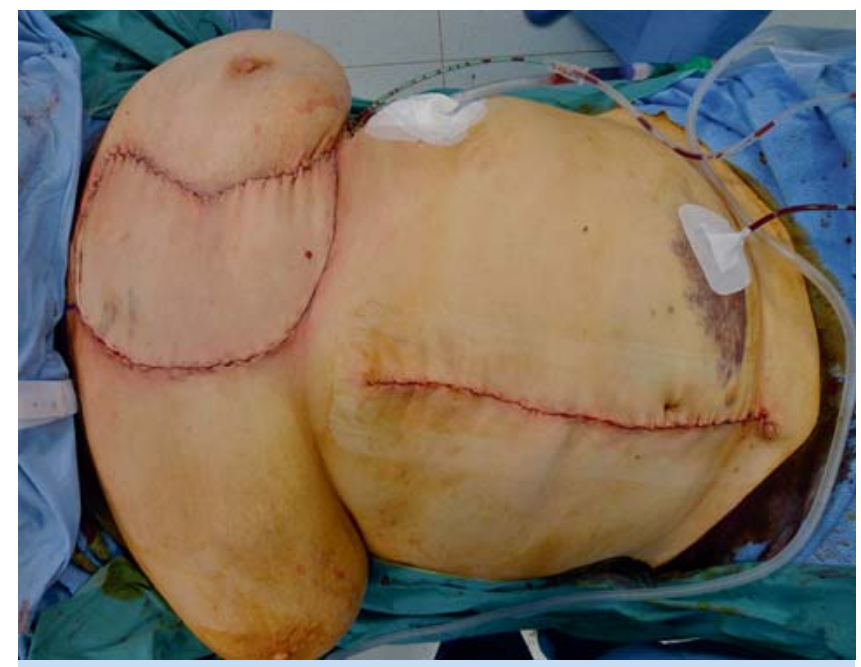

Fig. 5 Coverage of the defect using a pedicled VRAM-flap. 


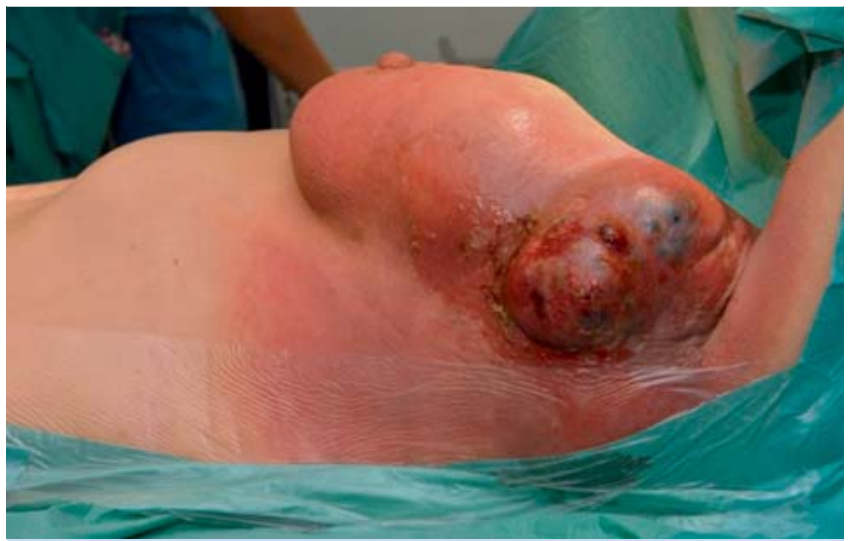

Fig. 6 Preoperative ulcerated breast carcinoma finding.

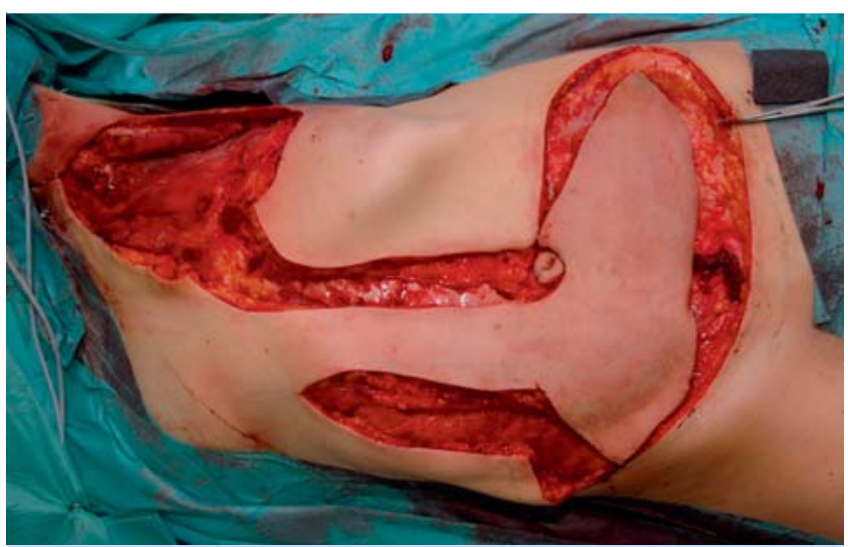

Fig. 8 Situs following resection of the tumour and lifted anchor flap.

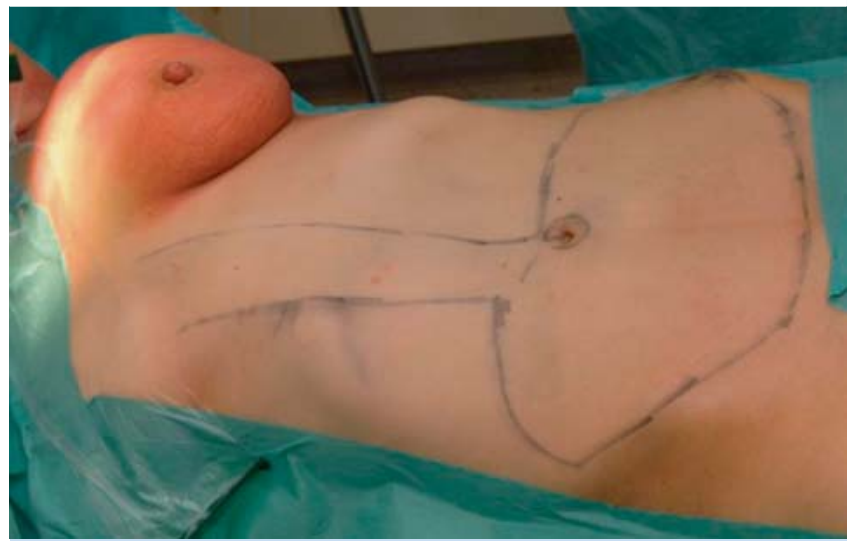

Fig. 7 Intraoperative planning of an anchor flap.

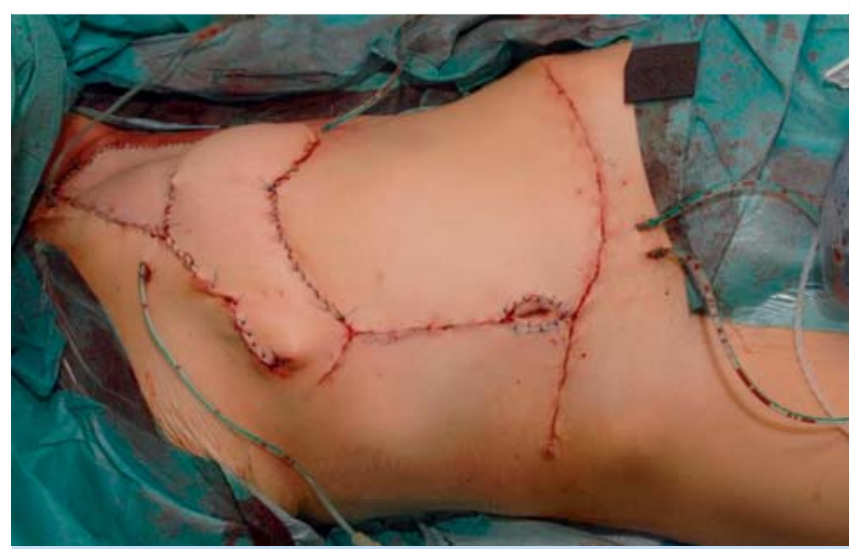

Fig. 9 Situs after anchor flap is sewn in and donor site has been closed by means of an abdominoplasty with umbilical repositioning. comparison to the inferior epigastric vessels. So, in the case of a cranially pedicled flap from the lower abdomen, perfusion disorders and partial necrosis can occur, particularly in the lateral portions.

Because free flap-plasties can be performed with the same or even a higher degree of safety than local flap-plasties as a result of the increasing improvement of microsurgical techniques, the trend with regard to flap-plasties from the lower abdomen is towards using free grafts based on the inferior epigastric vessels (see also TRAM/DIEP in the section on free flap-plasties). Nevertheless, this form of flap-plasty remains a good option for defect coverage, especially in the case of very expansive findings.

A case report of a patient with ulcerated breast carcinoma and defect coverage with an anchor flap is shown in $\bullet$ Figs. 6 to 9 .

\section{Latissimus dorsi muscular flap}

The myocutaneous latissimus dorsi flap is lifted pedicled to its thoracodorsal vessels while in a lateral position. It may be lifted simply as a muscular flap or as a myocutaneous flap $[25,26]$. One further modification is the lifting of the skin graft above the anterior rim of the latissimus and the dissection of the perforator vessels running through the muscle up to the outlet from the arteria subscapularis (thoraco-dorsal artery perforator flap; TAPflap). This way the muscle and its innervation are preserved, however only smaller grafts can be lifted [27]. If muscles and overlying skin grafts are lifted, it is advisable to lift a graft of sufficient size or to subject the perforator vessels to Doppler imaging beforehand so that a secure blood supply is guaranteed for the skin graft. Due to its reliable vascular supply, its proportions, the relatively simple dissection and the moderate donor site defect, the latissimus flap has proven itself in the coverage of defects of the thoracic cage [28]. As a result of its volume, it can also seal intra-thoracic defects. Flap losses rarely occur with pedicled flap-plasties provided there is careful dissection. However, in case of any doubt, particularly following axilla dissections, the presence of the supplying vessel must be examined, e.g. using Doppler imaging. In order to guarantee as much supply security as possible, the flap can also be lifted as a transposition-rotation flap. In this case, the parascapular vessel is included via the remaining cutaneous pedicle. The resulting donor site defect can undergo a split skin graft. While this does mean a compromise in terms of aesthetics, a larger flap can, however, be lifted and close up the relevant defects if the anchor flap is not an option (๑ Figs. 10 to 12).

\section{Omentum majus flap}

The omentum majus is a reserve option for closing defects in the anterior throracic wall. Pedicled to the unilateral or bilateral gastro-omental vessels, it can be lifted by means of a paramedian incision from the xiphoid process to beneath the umbilicus [29]. 


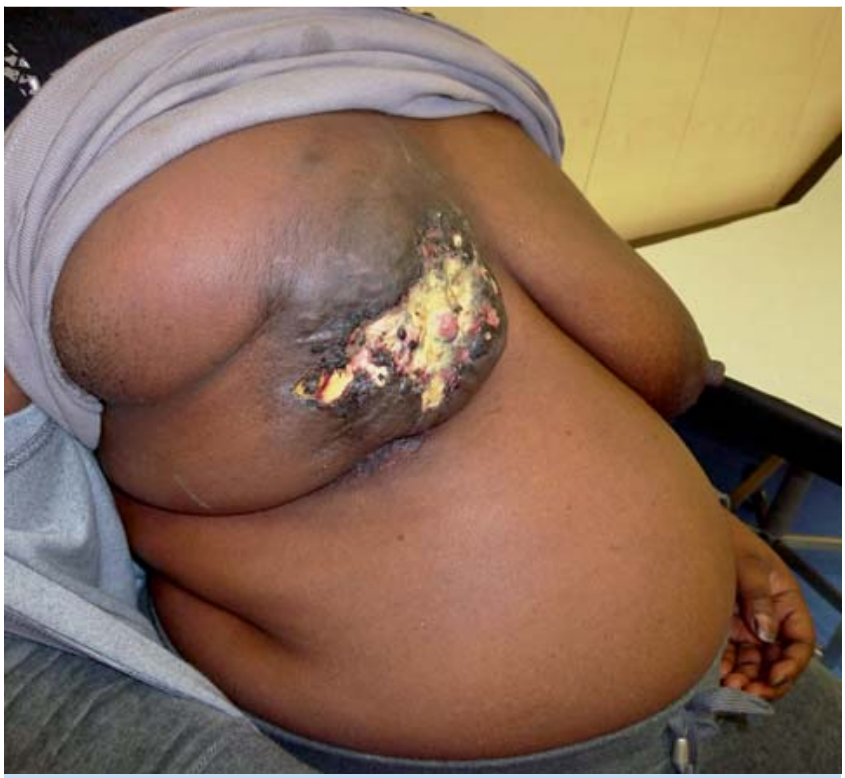

Fig. 10 Preoperative situs of a patient with ulcerated breast carcinoma.

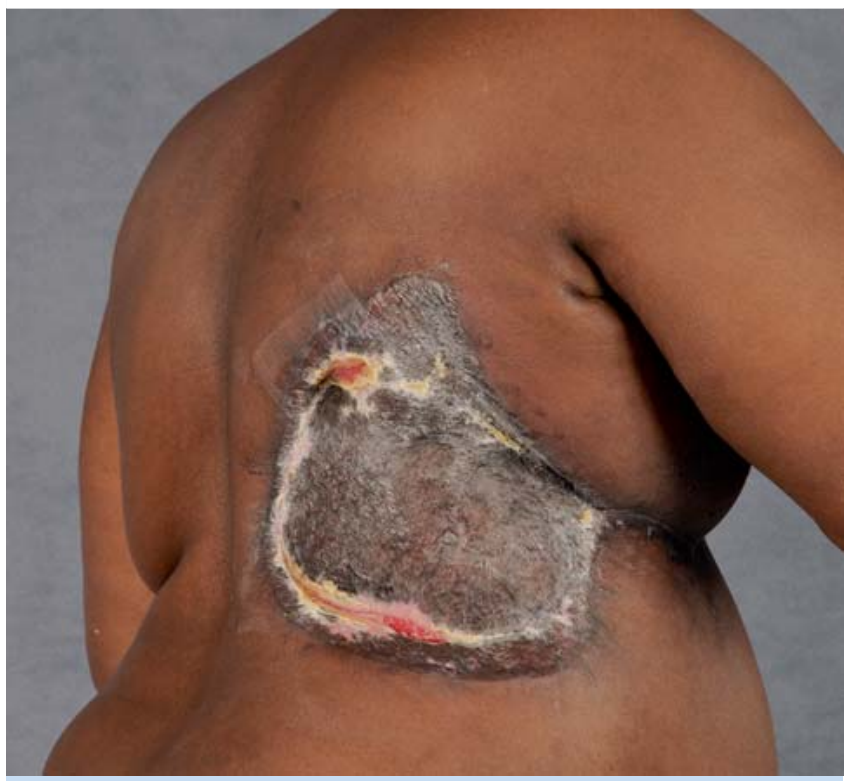

Fig. 12 Donor site of the latissimus flap which required split skin graft due to the size. There are wound healing complications cranially and caudally which underwent conservative treatment.

Whether or not the omentum is the desired size cannot be determined until after opening up the abdominal region. Occasionally, adhesions must be painstakingly removed and the net raised from the stomach in order to achieve the appropriate rotational radius. Furthermore, a gap must remain in the abdominal wall so that the pedicle can be guided outwardly through it in the direction of the thoracic wall. Even though such a fear of a "twocavity-operation" is over-exaggerated, this flap should only be lifted with the relevant experience and any potential complications such as intestinal perforations and bleeding can be contained. Due to its great plasticity, the omentum is well placed for

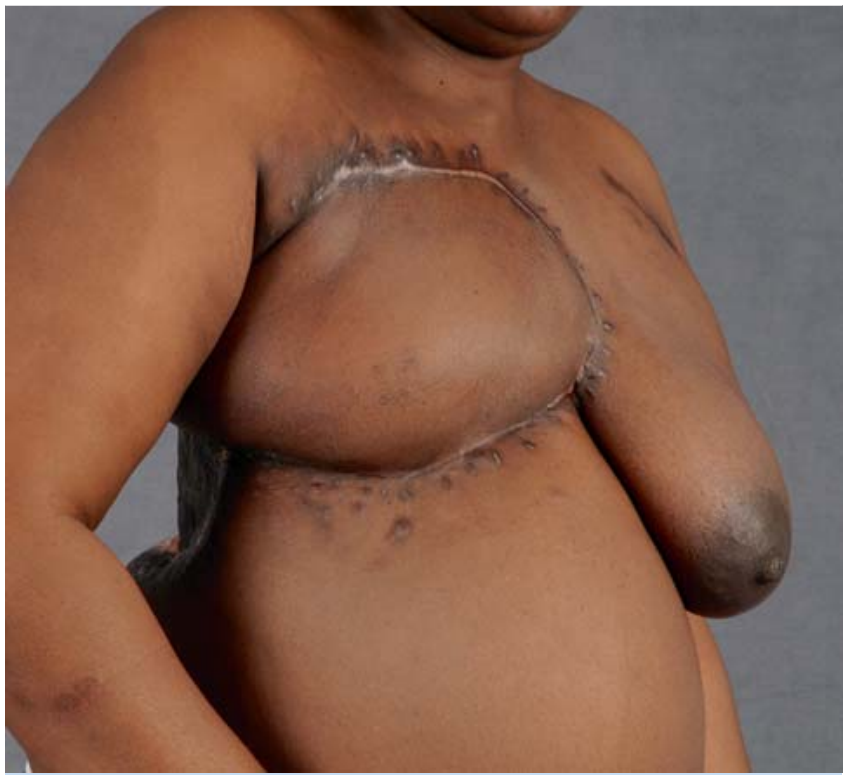

Fig. 11 Postoperative situs after pedicled latissimus flap-plasty with complete healing of the skin graft.

obliterating dead space. It must, however, always be covered by split skin and achieves only modest aesthetic results following secretion which often lasts a while and frequent partial secondary healing.

A meta-analysis [30] demonstrated that the overall complication rates of myoplasty and omentoplasty are comparable and can still be improved through laparoscopic exposure of the omentum or microsurgical omental transplantation. Due to the relatively high epigastric hernia rate [31-33] and the disadvantages mentioned, it remains as nothing more than a fallback option in special cases in our view.

\section{Free flap-plasties}

In the event that pedicled flap-plasties are not an option on account of prior operations or radiotherapy, free flap-plasties may be used. These techniques also make a useful addition to the reconstructive armamentarium as a fall-back procedure in the event of failed coverage attempts using local options. Fasciocutaneous or myocutaneous flap-plasties from the back for example (parascapular flap) or the thigh (anterior lateral thigh [ALT] (- Figs. 13 to 15); Tensor-fasciae-latae-[TFL-]flap). One frequently used donor area is the abdominal region with the transverse rectus abdominus myocutaneous flap (TRAM) or its muscle-preserving variation (ms-TRAM) as well as the perforator-based deep inferior epigastric artery perforator flap (DIEP). These flaps also have a certain volume depending on the constitution of the patient, so breast reconstruction beyond simple defect coverage can also be achieved or sufficient tissue is available to improve the local situation. Figs. 16 and 17 show a patient with ulcerated axillary breast carcinoma metastasis. Due to significantly reduced arm mobility in the case of scar contractures, the emphasis here was placed on the improvement of the local situation after a detailed explanation of the treatment options. By means of a DIEP flap-plasty, connected to the mammaria interna vessels, the existing scarred cords were able to be dispersed and the mobility of the shoulder significantly improved. Because 


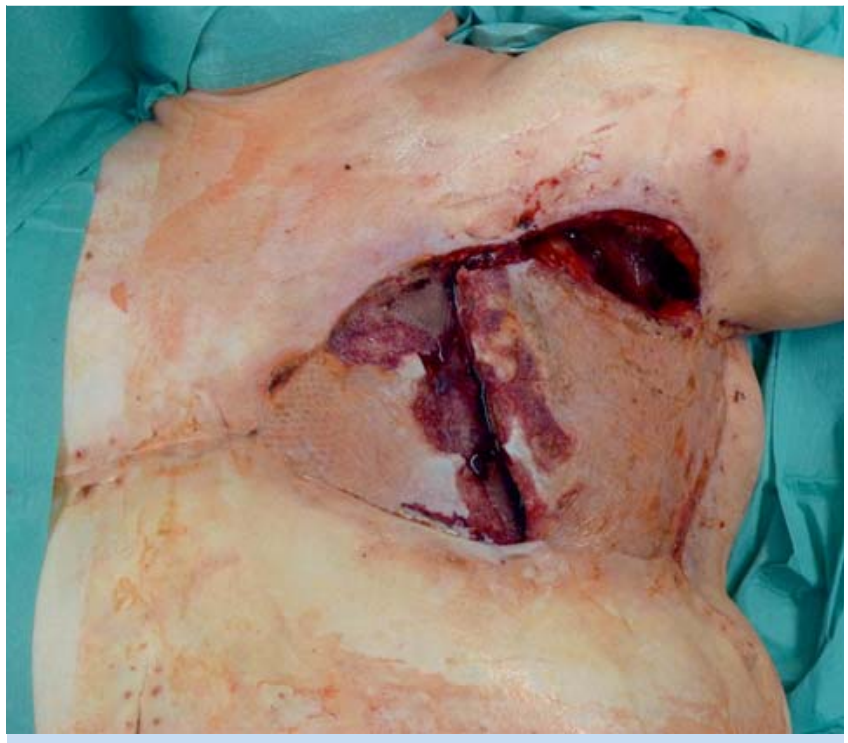

Fig. 13 Wound healing disorder following ablation of the breast in the case of carcinoma and defect coverage by means of VRAM and pedicled latissimus dorsi flap-plasty. In this the flaps were lifted simply as muscular flaps without a skin paddle, something which we advise against on account of the higher complication rate and the smaller size of the flaps.

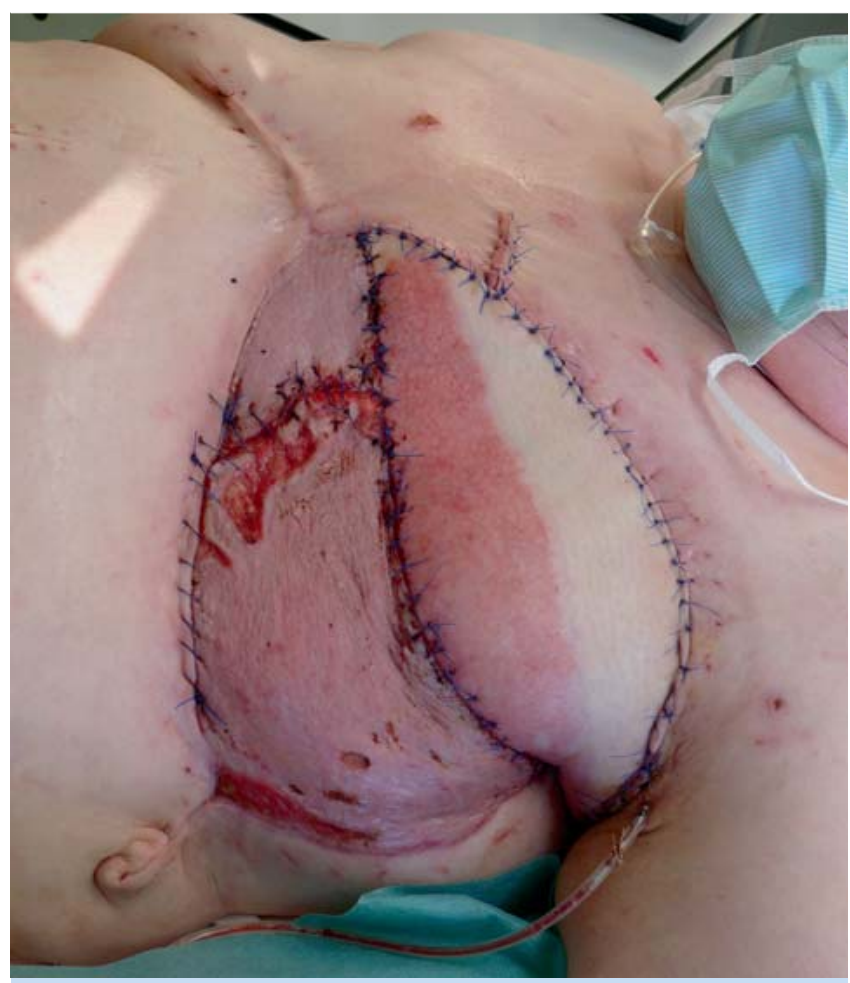

Fig. 15 Postoperative situs with well-supplied ALT flap-plasty and successful defect closure.

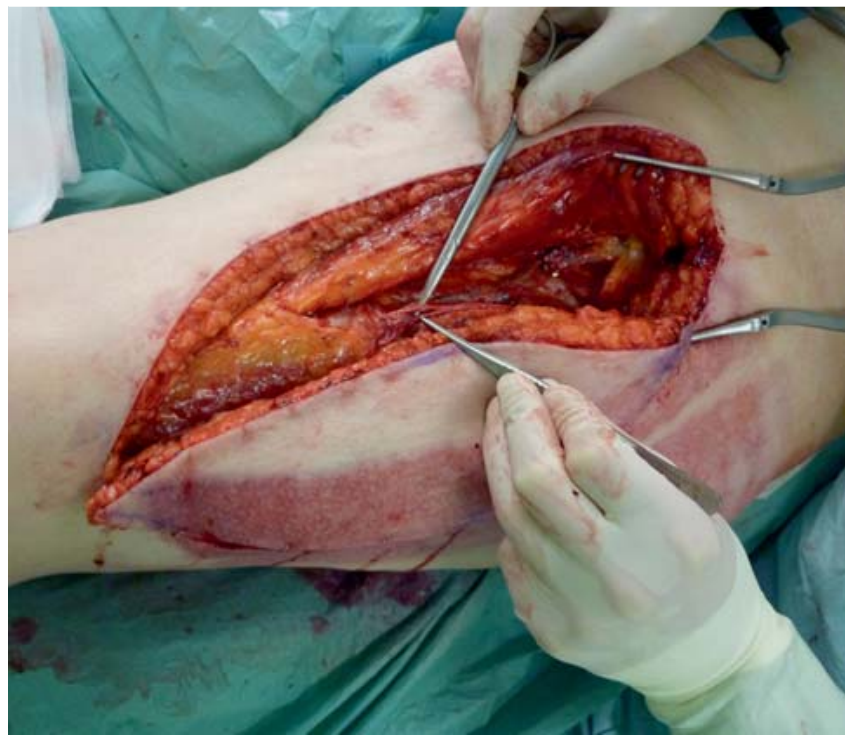

Fig. 14 Lifting of an anterior-lateral-thigh-flap (ALT) with view of the supply perforator vessel (the colour and texture change is caused by a prior split skin removal).

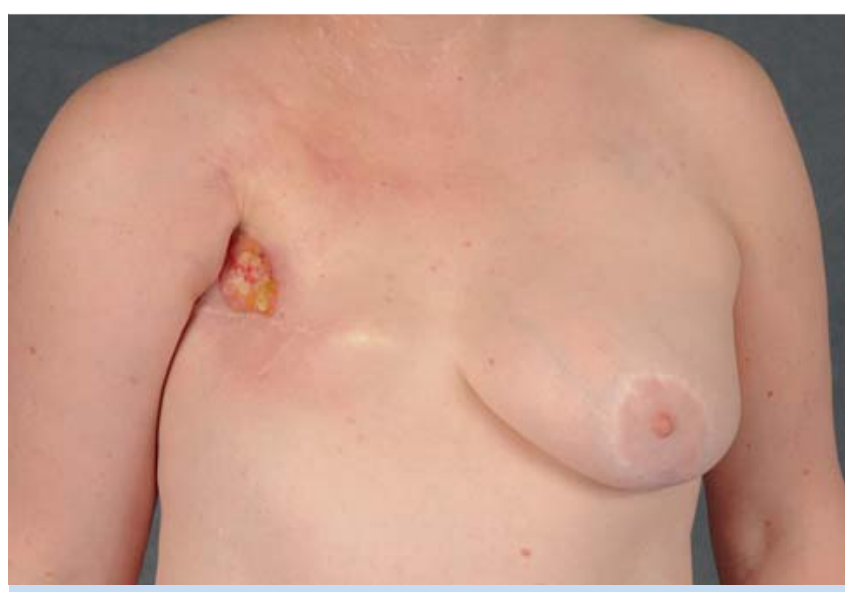

Fig. 16 Preoperative situs of a patient, condition after ablation of the right breast for carcinoma and ulcerated axillary metastasis.

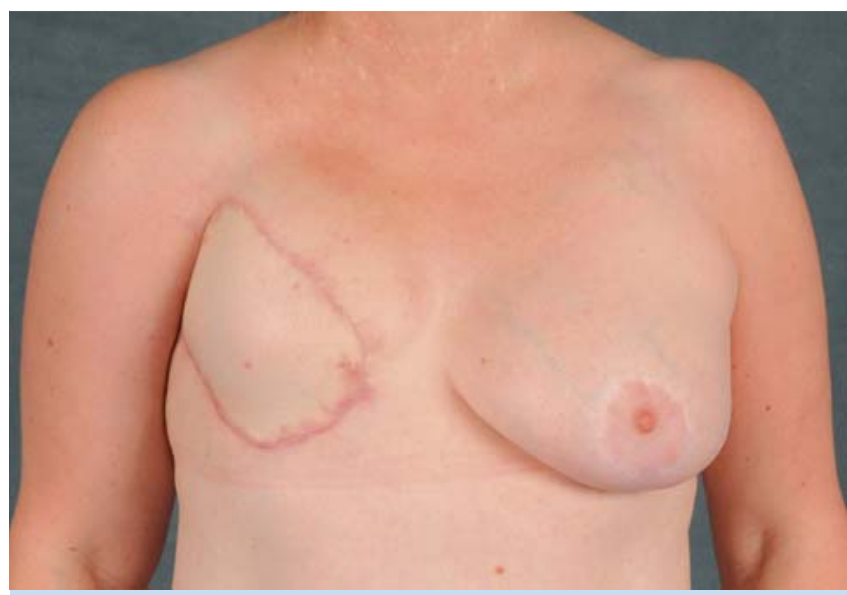

Fig. 17 Postoperative situs after defect closure with DIEP. 


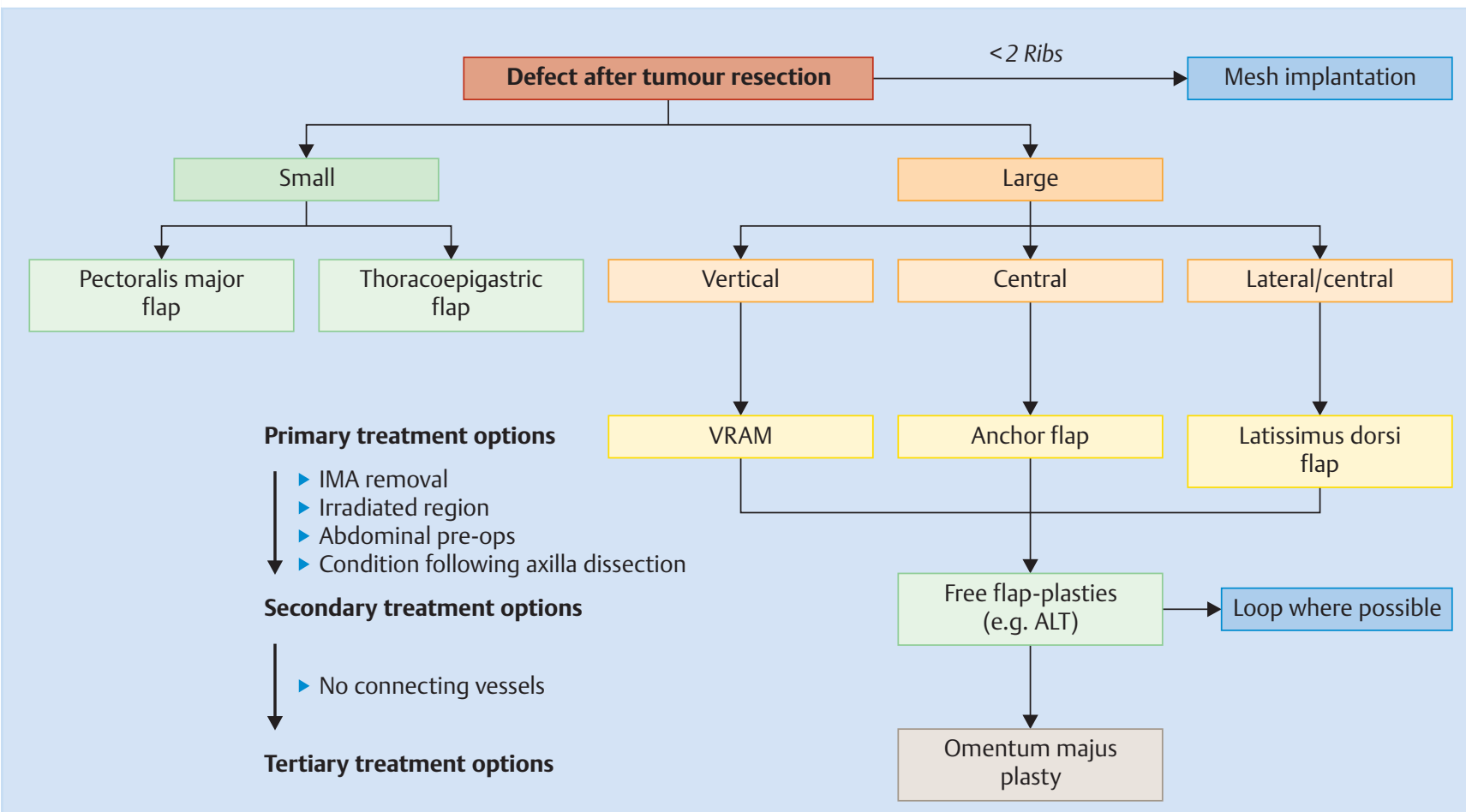

Fig. 18 Therapy algorithm for defect coverage of the thoracic wall.

the patient expressly refused the formation of a breast mound, but was however in a very good general condition, this flapplasty was able to be selected with minimal donor site morbidity. The mammaria interna vessels are the primary connecting vessels, depending on the finding, the thoraco-dorsal vessels can also act as connectors. In the event that these are not available, an arteriovenous loop between the cephalic vein and the thoracoacromial artery, where the vena cephalica is dissected from the upper arm in a distal direction, stripped to the required length and anastomosed with the arteria thoracoacromialis, can constitute an effort-intensive solution [34].

The donor site morbidity of free flap-plasties is comparatively low, especially if the donor site can be closed primarily $[35,36]$. It is not unusual for free flap-plasties to require operation times of over 6 hours and they are not suitable for all patients, particularly those at an advanced stage of progression. They also require the relevant microsurgical expertise and intensive monitoring in order to quickly detect any perforation disorders and, if need be, to guarantee an emergency anastomosis revision.

\section{Discussion \\ $\nabla$}

The indication for operation in patients with an advanced tumour affecting the thoracic wall often comes into being on account of pain, ulceration, haemorrhage or odour nuisance resulting from sloughing tumours. Their general condition is usually restricted, a long history of illness preceded and mental capacity is also reduced. With this in mind, larger interventions must be viewed critically. Reduced life expectancy is also frequently used as an argument against intervention, in palliative situations in particular. Experience in our own patient population and further studies do however show a high degree of patient satisfaction following these interventions because social participation is made possible for patients again. If we weigh up the average 3-week hospital stay against the remaining life expectancy following thoracic wall resectioning, intervention seems justified if the level of suffering is reduced and the remaining time can be made worth living [28]. The low 30-day mortality rates and the limited effects on the lung function parameters back up the concern about the negative consequences of thoracic wall resectioning and reconstruction at least partially [10,28,37-40].

In international references there is a complication rate of almost $30 \%$ which reflects both the severity of the underlying disease and the reduced condition of the patients as well as the complexity of these interventions $[4,6,41]$.

Such disruptions to the wound healing process cause the period of hospitalization to be extended and quality of life to deteriorate. Adjuvant radiotherapy or chemotherapy can also be delayed. Secure pedicles flap-plasties are sufficiently available for most thoracic wall defects and should be preferred owing to the simple and quick dissection as well as their low complication rate $[2,4$, $41,42]$. Small defects qualify for a pectoralis or thoracoepigastric flap, for larger vertical defects we prefer the VRAM-flap, large central defects are best suited to an anchor flap, lateral for an anchor or latissimus flap. We prefer free flap-plasties over the omentum as a reserve option due to the lower donor site morbidity. On account of the size of the flap and the potential back position and thus the better possibility of connecting to the mammaria interna vessels, here it is primarily the anterior lateral thigh flap (ALT) which is used [43]. A recapitulatory therapy algorithm is depicted in $\bullet$ Fig. 18. 


\section{Conclusions}

\section{$\nabla$}

Advanced breast tumours can also be adequately treated by plastic surgery reconstruction procedures. Defects which result from radical resection, sometimes involving the thoracic wall sections, can usually be safely covered using a pedicled flap-plasty from the torso.

Free flap-plasties as well as the omentum majus remain as fallback options.

These techniques may be applied not only when aiming to cure, but also in palliative situations where, e.g. in the case of ulcerated, painful or sloughing tumours, the patient's quality of life can be significantly improved. Because, even in the case of partial thoracic wall resection, the impact on the respiratory mechanism remains easy to compensate and the donor site morbidity of flapplasties is moderate, a practical treatment option can be offered even in the case of advanced tumours.

In addition to forming the right indication, under consideration of the individual patient profile and the relevant surgical techniques, an interdisciplinary cooperation of all disciplines involved is required above all.

Only by doing so can patients with such extensive tumours be cared for optimally.

\section{Conflict of Interest}

\section{$\nabla$}

None.

\section{References}

1 Granick MS, Larson DL, Solomon MP. Radiation-related wounds of the chest wall. Clin Plast Surg 1993; 20: 559-571

2 Steinau HU, Hebebrand D, Vogt P et al. [Reconstructive plastic surgery of thoracic wall defects]. Chirurg 1997; 68: 461-468

3 Vogt PM, Busch K, Peter FW et al. [Plastic reconstruction of the irradiated thoracic wall]. Langenbecks Arch Chir Suppl Kongressbd 1998; 115: 507-511

4 Arnold PG, Pairolero PC. Chest-wall reconstruction: an account of 500 consecutive patients. Plast Reconstr Surg 1996; 98: 804-810

5 Losken A, Thourani VH, Carlson GW et al. A reconstructive algorithm for plastic surgery following extensive chest wall resection. Br J Plast Surg 2004; 57: 295-302

6 Chang RR, Mehrara BJ, Hu QY et al. Reconstruction of complex oncologic chest wall defects: a 10-year experience. Ann Plast Surg 2004; 52: 471-479; discussion 479

7 Chapelier A, Macchiarini P, Rietjens $M$ et al. Chest wall reconstruction following resection of large primary malignant tumors. Eur J Cardiothorac Surg 1994; 8: 351-356; discussion 357

8 Koch $\mathrm{H}$, Tomaselli F, Pierer $\mathrm{G}$ et al. Thoracic wall reconstruction using both portions of the latissimus dorsi previously divided in the course of posterolateral thoracotomy. Eur J Cardiothorac Surg 2002; 21: 874878

9 Lardinois D, Müller M, Furrer $M$ et al. Functional assessment of chest wall integrity after methylmethacrylate reconstruction. Ann Thorac Surg 2000; 69: 919-923

10 Bury TF, Reece GP, Janjan NA et al. Closure of massive chest wall defects after full-thickness chest wall resection. Ann Plast Surg 1995; 34: 409414

11 Dieterich M, Dieterich H, Moch $H$ et al. Re-excision rates and local recurrence in breast cancer patients undergoing breast conserving therapy. Geburtsh Frauenheilk 2012; 72: 1018-1023

12 Grischke E-M, Wallwiener D, Souchon $R$ et al. Isolated loco-regional recurrence of breast cancer - established and innovative therapy concepts. Geburtsh Frauenheilk 2013; 73: 611-622

13 Ebner FK, Friedl TWP, deGregorio $N$ et al. Does non-placement of a drain in breast surgery increase the rate of complications and revisions? Geburtsh Frauenheilk 2013; 73: 1128-1134
14 Dieterich M, Faridi A. Biological matrices and synthetic meshes used in implant-based breast reconstruction - a review of products available in Germany. Geburtsh Frauenheilk 2013; 73: 1100-1106

15 Deschamps C, Tirnaksiz BM, Darbandi $R$ et al. Early and long-term results of prosthetic chest wall reconstruction. J Thorac Cardiovasc Surg 1999; 117: 588-591; discussion 591-592

16 Kroll SS, Walsh G, Ryan B et al. Risks and benefits of using Marlex mesh in chest wall reconstruction. Ann Plast Surg 1993; 31: 303-306

17 Riedel K, Kremer T, Hoffmann H et al. [Plastic surgical reconstruction of extensive thoracic wall defects after oncologic resection]. Chirurg 2008; 79: 164-174

18 Saint-Cyr M, Wong C, Schaverien $M$ et al. The perforasome theory: vascular anatomy and clinical implications. Plast Reconstr Surg 2009; 124: 1529-1544

19 Ariyan S. The pectoralis major myocutaneous flap. A versatile flap for reconstruction in the head and neck. Plast Reconstr Surg 1979; 63: 73-81

20 Daigeler A, Falkenstein A, Pennekamp $W$ et al. Sternal osteomyelitis: long-term results after pectoralis muscle flap reconstruction. Plast Reconstr Surg 2009; 123: 910-917

21 Arnold PG, Pairolero PC. Use of pectoralis major muscle flaps to repair defects of anterior chest wall. Plast Reconstr Surg 1979; 63: 205-213

22 Jurkiewicz MJ, Bostwick J 3rd, Hester TR et al. Infected median sternotomy wound. Successful treatment by muscle flaps. Ann Surg 1980; 191: 738-744

23 Mathes SJ. Chest wall reconstruction. Clin Plast Surg 1995; 22: 187198

24 Daigeler A, Simidjiiska-Belyaeva M, Drucke D et al. The versatility of the pedicled vertical rectus abdominis myocutaneous flap in oncologic patients. Langenbecks Arch Surg 2011; 396: 1271-1279

25 McCraw JB, Penix JO, Baker JW. Repair of major defects of the chest wall and spine with the latissimus dorsi myocutaneous flap. Plast Reconstr Surg 1978; 62: 197-206

26 Olivari $N$. The latissimus flap. Br J Plast Surg 1976; 29: 126-128

27 Schwabegger AH, Bodner G, Ninkovic M et al. Thoracodorsal artery perforator (TAP) flap: report of our experience and review of the literature. Br J Plast Surg 2002; 55: 390-395

28 Daigeler A, Druecke D, Hakimi $M$ et al. Reconstruction of the thoracic wall-long-term follow-up including pulmonary function tests. Langenbecks Arch Surg 2009; 394: 705-715

29 Lee AB, Schimert G, Shaktin S et al. Total excision of the sternum and thoracic pedicle transposition of the greater omentum; useful strategems in managing severe mediastinal infection following open heart surgery. Surgery 1976; 80: 433-436

30 van Wingerden JJ, Lapid $O$, Boonstra PW et al. Muscle flaps or omental flap in the management of deep sternal wound infection. Interact Cardiovasc Thorac Surg 2011; DOI: 10.1510/icvts.2011.270652

31 Milano CA, Georgiade G, Muhlbaier LH et al. Comparison of omental and pectoralis flaps for poststernotomy mediastinitis. Ann Thorac Surg 1999; 67: 377-380; discussion 380-381

32 Jurkiewicz MJ, Arnold PG. The omentum: an account of its use in the reconstruction of the chest wall. Ann Surg 1977; 185: 548-554

33 Hultman CS, Culbertson JH, Jones GE et al. Thoracic reconstruction with the omentum: indications, complications, and results. Ann Plast Surg 2001; 46: 242-249

34 Reichenberger MA, Harenberg PS, Pelzer $M$ et al. Arteriovenous loops in microsurgical free tissue transfer in reconstruction of central sternal defects. J Thorac Cardiovasc Surg 2010; 140: 1283-1287

35 Fischer S, Klinkenberg M, Behr B et al. Comparison of donor-site morbidity and satisfaction between anterolateral thigh and parascapular free flaps in the same patient. J Reconstr Microsurg 2013; 29: 537-544

36 Klinkenberg M, Fischer S, Kremer T et al. Comparison of anterolateral thigh, lateral arm, and parascapular free flaps with regard to donorsite morbidity and aesthetic and functional outcomes. Plast Reconstr Surg 2013; 131: 293-302

37 al-Kattan KM, Breach NM, Kaplan DK et al. Soft-tissue reconstruction in thoracic surgery. Ann Thorac Surg 1995; 60: 1372-1375

38 Pfannschmidt J, Geisbusch P, Muley T et al. Surgical resection of secondary chest wall tumors. Thorac Cardiovasc Surg 2005; 53: 234-239

39 Tukiainen E, Popov P, Asko-Seljavaara S. Microvascular reconstructions of full-thickness oncological chest wall defects. Ann Surg 2003; 238: 794-801; discussion 801-802 
40 Walsh GL, Davis BM, Swisher SG et al. A single-institutional, multidisciplinary approach to primary sarcomas involving the chest wall requiring full-thickness resections. J Thorac Cardiovasc Surg 2001; 121: $48-60$

41 Mansour KA, Thourani VH, Losken A et al. Chest wall resections and reconstruction: a 25-year experience. Ann Thorac Surg 2002; 73: 17201725; discussion 1725-1726
42 Cohen M, Ramasastry SS. Reconstruction of complex chest wall defects. Am J Surg 1996; 172: 35-40

43 Wei FC, Jain V, Celik $N$ et al. Have we found an ideal soft-tissue flap? An experience with 672 anterolateral thigh flaps. Plast Reconstr Surg 2002; 109: 2219-2226; discussion 2227-2230 